\title{
Searching for ivermectin resistance in Dutch horses
}

\author{
D.C.K. van Doorn*, M. Eysker, F.N.J. Kooyman, J.A. Wagenaar, H.W. Ploeger \\ Department of Infectious Diseases and Immunology, Faculty of Veterinary Medicine, Utrecht University, Yalelaan 1, 3584 CL Utrecht, The Netherlands
}

\section{A R T I C L E I N F O}

\section{Article history:}

Received 4 March 2011

Received in revised form

19 September 2011

Accepted 21 September 2011

\section{Keywords:}

Cyathostominae

Macrocyclic lactones

Resistance

Questionnaire

\begin{abstract}
A B S T R A C T
A study was conducted to evaluate the occurrence of resistance against, in particular, ivermectin in cyathostomins in the Netherlands. Seventy horse farms were visited between October 2007 and November 2009. In initial screening, faecal samples were collected 2 weeks after deworming with either ivermectin, moxidectin or doramectin. Pooled faecal samples from a maximum of 10 horses were examined for worm eggs using a modified McMaster technique and for worm larvae after faecal larval cultures. In total 931 horses were involved. On 15 of 70 farms eggs and/or larvae were found. On 8 of these 15 farms a FECRT with ivermectin was performed on 43 horses. Efficacy of ivermectin against cyathostomins of $93 \%$ was found in one animal on one farm. Additionally, the strategies and efforts of the horse owners to control cyathostomins, as well as risk factors for the development of macrocyclic lactone resistance were evaluated with a questionnaire. Strikingly, many responders indicated that the control of cyathostomins in horses is achieved through very frequent deworming. Fourteen percent of these owners deworm seven times per year or more. On $34 \%$ of the 70 farms treatment was repeated within the Egg Reappearance Period of a product.
\end{abstract}

(c) 2011 Elsevier B.V. All rights reserved.

\section{Introduction}

Cyathostomins are the most prevalent horse helminths, with 50 species found in equids worldwide (Lichtenfels et al., 2008). Disease may occur in horses of all ages but young horses (1-4 year old) are more susceptible. To control infections, management measures should be applied (e.g. pasture rotation and reducing grazing density) supported by the use of anthelmintics. Several classes of anthelmintics have been approved for use against cyathostomins in horses. Benzimidazoles were introduced as anthelmintics for horses in the 1960s and pyrantel in 1970. The first representative of the macrocyclic lactones (MLs), ivermectin, was introduced in the early 1980s and moxidectin in the middle of the 1990s. (Pro)benzimidazole resistant cyathostomins are described since the 1960s

\footnotetext{
* Corresponding author. Tel.: +31 302532459 .

E-mail address: d.c.k.vanDoorn@uu.nl (D.C.K. van Doorn).
}

(Drudge and Elam, 1961) and in the 90s the first reports on pyrantel resistance appeared (Chapman et al., 1996). In 1994 Xiao showed that the efficacy of ML against adult cyathostomins was still 99\% (Xiao et al., 1994). Worldwide, several recent studies showed shortening of the Egg Reappearance Period (ERP) (Von Samson-Himmelstjerna et al., 2007; Lyons et al., 2008; Molento et al., 2008) which is considered to indicate resistance (Lyons et al., 2009). Once resistance is present, spreading of the resistant cyathostomin populations is likely by transport of horses.

In the Netherlands, as anywhere else, owners and veterinary practitioners rely heavily on frequent anthelmintic treatments to avoid disease. Therefore, it is not unlikely that reduced ML efficacy also may have developed in the Netherlands. In the present study we conducted a survey to evaluate the presence of ivermectin resistant cyathostomins in Dutch horses. On the same farms, owners were questioned about their worm control practice to determine a possible association between worm control intensity and presence of ML resistance. 
Table 1

Faecal Egg Count Reduction Test and larval culture counts on 43 horses from eight farms. After deworming EPG or LPG was mainly zero for most horses on a farm. Otherwise this was called individual EPG or LPG.

\begin{tabular}{|c|c|c|c|c|c|c|c|c|c|c|}
\hline \multirow[t]{2}{*}{ Farm } & \multirow{2}{*}{$\begin{array}{l}\text { Number of } \\
\text { horses on } \\
\text { the farm }\end{array}$} & \multirow{2}{*}{$\begin{array}{l}\text { Number of } \\
\text { FECRT } \\
\text { horses }\end{array}$} & \multicolumn{4}{|c|}{ Before deworming } & \multicolumn{4}{|c|}{ After deworming } \\
\hline & & & Mean EPG & EPG range & Mean LPG & LPG range & Mean EPG & Mean LPG & $\begin{array}{l}\text { Individual } \\
\text { EPG }\end{array}$ & $\begin{array}{l}\text { Individual } \\
\text { LPG }\end{array}$ \\
\hline 1 & 8 & 5 & 130 & $25-750$ & 108 & $5-450$ & 0 & 0 & 0 & 1 \\
\hline 2 & 40 & 3 & 300 & $25-700$ & 242 & $10-450$ & 0 & 0 & - & - \\
\hline 3 & 24 & 7 & 300 & $50-1350$ & 111 & $18-1300$ & 3.6 & 0.014 & 25 & 0.1 \\
\hline 4 & 55 & 12 & 250 & 50-1025 & 456 & $0-1640$ & 0 & 0 & - & - \\
\hline 5 & 110 & 12 & 444 & $75-1850$ & 1094 & $100-3750$ & 0 & 0 & - & - \\
\hline 6 & 25 & 1 & 200 & - & 30 & - & 0 & 0 & - & - \\
\hline 7 & 10 & 2 & 1450 & $700-2200$ & 554 & $3-1105$ & 0 & 2.5 & 0 & 5 \\
\hline 8 & 70 & 1 & 4300 & - & 520 & - & 0 & 0 & - & - \\
\hline
\end{tabular}

\section{Materials and methods}

\subsection{Selection of farms}

Between October 2007 and November 2009, 159 horse farms throughout the Netherlands were selected using an internet search. Horse farmers were asked to participate in a trial to evaluate the efficacy of MLs against strongylids. A farm was included if they had three horses or more that were kept on pasture together and the last used wormer was a macrocyclic lactone. Participating farms were included for a visit if deworming fell within one of three periods (October-December period 2007 and 2009 and April-July 2008). Of the 159 approached farms 66 were visited. In addition, 30 veterinary clinics were approached to more efficiently seek farms with positive faecal egg counts after deworming. This led to four more farms that were visited. This study was not designed as a crosssectional study as farms were not randomly selected.

\subsection{Questionnaire}

During the first visit, the owners were asked questions about the farm, pasture management and housing, deworming and parasitic problems. This was based on the questionnaire of Osterman Lind et al. (2007).

\subsection{Screening}

Fourteen days after deworming 70 farms were visited for the first time to collect faecal samples. The samples were pooled with a maximum of 10 horses per sample (Eysker et al., 2007). On several larger farms faecal material for more than one pooled sample (2-6) was collected. In total 115 pooled faecal samples were examined. The decision on how the samples were pooled depended on how the groups of horses were maintained on pasture.

Pools consisted of $3.0 \mathrm{~g}$ from each individual sample and these were mixed thoroughly. A modified McMaster method with saturated $\mathrm{NaCl}$ solution (MAFF, 1986) was done with $3.0 \mathrm{~g}$ faeces from the pooled sample and 4 chambers were counted per pooled sample, resulting in a detection limit of 25 eggs per gram of faeces (EPG). For the pooled cultures each horse contributed equal amounts of faeces to a thoroughly mixed sample from which $25 \mathrm{~g}$ was cultured in duplicate in glass jars for $10-12$ days at $21^{\circ} \mathrm{C}$ (Borgsteede and Hendriks, 1973). After the culture period the jars were filled with tap water and turned upside down on Petri dishes. The following day the larvae were collected, differentiated (Thienpont et al., 2003) and counted to determine the numbers of larvae per gram faeces (LPG), with an overall detection limit of 0.04 LPG (or 0.4 LPG per individual horse).

\subsection{Faecal Egg Count Reduction Test (FECRT)}

If screening showed a positive EPG and/or LPG the second and third visit to the farm were planned in order to perform a FECRT. The second visit was planned after the assumed ERP period had elapsed. Faeces from individual horses was examined with the McMaster technique, as well as that $25 \mathrm{~g}$ of faeces from each horse was cultured as described above. Examinations were done on day 0 and day 14 after ivermectin treatment (Eqvalan ${ }^{\circledR}$ or Equimectin ${ }^{\circledR}$, $200 \mu \mathrm{g}$ per $\mathrm{kg}$ bodyweight. Bodyweight (BW) was estimated using a girth tape (Coles et al., 2006). In some cases, the weight was estimated visually by two people followed by adding $10 \%$ to the mean of both visual estimations. This was done by a trained student and the owner because we felt the girth measurement in certain breeds underestimates the actual weight. An efficacy of less than $95 \%$ for an individual animal indicated suspected resistance (Craven et al., 1998; Coles et al., 2006). We were able to perform a FECRT on 8 from the in total 15 farms with positive egg counts or larval cultures that were found within the screening.

\section{Results}

\subsection{Screening and FECRT}

Fifteen farms (16 pools) had a positive EPG and/or LPG 14 days after deworming. On 8 of these farms an FECRT was performed on individual animals with positive EPG's. Taken together, 931 horses were investigated within the screening procedure and an FECRT was performed on 43 horses. EPG and LPG reduction was $100 \%$ on 6 farms (Table 1). On farm 3 (Table 1) a yearling with a reduction in EPG of $93 \%$ 
(from 350 to 25 EPG) was found, while LPG reduction after deworming was $99.6 \%$. The last dewormer that was used by the farmer turned out to be doramectin, a non-registered product for horses. On farm 7 a 3 year old Shetland pony stallion had a LPG of 1105 before and 5 LPG after deworming (Table 1).

FECRT was not performed on all 15 farms with positive egg counts or positive larval cultures because either EPG was too low or the farmer did not cooperate.

\subsection{Questionnaire}

From the 159 farms that were contacted by phone, 110 (70\%) were willing to cooperate. We could not include all of the 110 farms in the screening and FECRT study because the deworming schedule not always allowed a first visit during our three sampling periods.

The mean number of animals on the 70 farms that were investigated was 61 (5-400). Half of the farms that were investigated were raising farms that stock yearlings, 2 and 3 year olds for a couple of years before they return to their owners. Five (7\%) from the 70 investigated farms had more than 0.5 ha grazing land per horse available. Fifteen farms (21\%) said they remove faeces from pasture regularly, 9 said they do this at least once every 2 weeks. Forty-six owners (66\%) indicated that they had problems with cyathostomins in the recent past and this was based on clinical signs only. Faecal examination before considering deworming (monitoring) was routinely done on just 2 farms (3\%), sometimes on 25 farms (36\%) and never on 42 farms (61\%).

Overall mean number of treatments was 5 times per year (range between 2 and 10 times). Anthelmintic doses were established on 2 farms (3\%) by weighing with a scale. On 18 farms (26\%) body weight was estimated prior to dosing. The other 50 horse caretakers (71\%) and/or veterinarians apparently did not consider the weight of the horses in relation to the amount of product that had to be applied. The last treatment was performed with ivermectin on 38 farms (54\%), with moxidectin on 29 (41\%), and with doramectin on 2 farms (3\%). On 1 farm they were not sure whether they used ivermectin or moxidectin. Twenty farms (29\%) always use the same active ingredient, on 2 farms (3\%) the care takers did not know which ingredients normally were used and the other 48 farms (69\%) rotated active substances or thought they did. On 34\% of these premises treatment was repeated within the Egg Reappearance Period of a product. Half of the 70 farms treated all the horses at the same time. Just over $50 \%$ of the farmers kept new horses in quarantine, and from these horses about $40 \%$ stayed in quarantine for more than 2 weeks.

\section{Discussion and conclusion}

To assess whether ivermectin resistance is present in the Netherlands we conducted a survey. Because we were merely interested in the occurrence of ivermectin resistance rather than actual prevalence, we included 35 raising farms in our screening procedure. In young animals strongyle eggs return sooner after deworming and egg counts get higher than in adult animals (Döpfer et al., 2004).
For screening purposes the approach by using pooled samples allowed to include more farms compared to the more labour intensive FECRT. Furthermore, FECRT has shown to be an insensitive technique to detect anthelmintic resistance. Using larval cultures within the screening procedure and FECRT helps to accomplish higher sensitivity (Bello and Allen, 2009). Within the screening procedure 15 farms were found positive, with either eggs or larvae after treatment with a ML. However, FECRT performed on 8 out of these 15 farms, did not result in proven resistance on these farms. Just one horse showed a 93\% efficacy in the FECRT. Underdosing of the horses by the owners may have led to the positive faecal examinations within the screening procedure. Underdosing was excluded within the FECRT procedure, which may account for the fact that less positive FEC and/or larval cultures were found. Since both used products were found efficacious as measured with FECRT, no difference between original and generic product was found.

Although ivermectin resistance could not be demonstrated in the present study, it should be noted that shortening of the ERP after use of a ML is probably the first indication of cyathostomin resistance (Lyons et al., 2009). As the used method did not allow for registering this shortening of the ERP, developing resistance towards ivermectin might have been missed. Therefore yearly screening for developing resistance should be applied not only 2 weeks but also 4 or 5 weeks after treatment with a ML.

The results from the questionnaire were comparable with those from Osterman Lind et al. (2007) and Von Samson-Himmelstjerna et al. (2009) and showed that horse owners/farmers were lacking knowledge on the epidemiology of cyathostomins, pasture management, and time and frequency of deworming for an efficient worm control policy. The frequency of treatment was, with an average of 5 times per year, high on most farms. One farm, for example, used moxidectin once every 6 weeks whereas the product is registered for use against strongylids once every 12 weeks in the Netherlands. Pasture rotation on the questioned 70 farms was always aimed at providing sufficient grass for the horses. However, none of the farmers tried to use pasture rotation as a means of worm control. Only 9 out of the 15 farms that said they remove faeces from pasture regularly did this at least once every 2 weeks. Removing faeces from pasture would lower the infection pressure enormously but probably needs to be done every week to keep the pasture sufficiently safe (Herd, 1986). Faecal examination before deworming (monitoring) was only done on 2 farms. A large majority of adult horses will have a negative EPG at the time of deworming if this is based on ERP (Comer et al., 2006). Half of the 70 visited farms were raising farms and blind treatments based on the ERP may be acceptable in young animals, in particular yearlings, considering that egg counts usually return rapidly to fairly high levels after the ERP. Considering that $34 \%$ of these 70 owners dewormed frequently within the ERP or in the winter when the horses were not on pasture, frequency of deworming could have been lower on most of these farms (Döpfer et al., 2004).

Fifty percent of the farms treated all horses present on the farm at the same time and by doing so were 
increasing the selection pressure for anthelmintic resistance. In a group of horses the individuals with low egg shedding should preferably be left untreated to create refugium (van Wyk, 2001). Newly introduced horses should be kept in quarantaine and after this period not turned out on pasture until a faecal check is performed. Clearly, not all horse owners did apply proper quarantine schemes.

Despite the intensive use of ML's, we were not able to detect ivermectin resistance with FECRT, apart from an apparent reduced efficacy of $93 \%$ in just one horse.

\section{Acknowledgements}

We would like to thank Eva de Vries, DVM, Jasper Simons, DVM and Muriel Paauwe, DVM, and the horse owners for their collaboration, and the Ministry of Economics, Agriculture and Innovation for their financial support.

\section{References}

Bello, T.R., Allen, T.M., 2009. Comparison of two fecal egg recovery techniques and larval culture for cyathostomins in horses. AJVR 70, 571-573.

Borgsteede, F.H.M., Hendriks, J., 1973. Een kwantitatieve methode voor het kweken en verzamelen van infectieuze larven van maagdarmwormen. Tijdschr Diergeneeskd 98, 280-285.

Chapman, M.R., French, D.D., Monahan, C.M., Klei, T.R., 1996. Identification and characterization of a pyrantel pamoate resistant cyathostome population. Vet. Parasitol. 66, 205-212.

Coles, G.C., Jackson, F., Pomroy, W.E., Prichard, R.K., Von SamsonHimmelstjerna, G., Silvestre, A., Taylor, M.A., Vercruysse, J., 2006 The detection of anthelmintic resistance in nematodes of veterinary importance. Vet. Parasitol. 136, 167-185.

Comer, K.C., Hillyer, M.H., Coles, G.C., 2006. Anthelmintic use and resistance on thoroughbred training yards in the UK. Vet. Rec. 158, 596-598.

Craven, J., Bjorn, H., Henriksen, S.A., Nansen, P., Larsen, M., Lendal, 1998 Survey of anthelmintic resistance on Danish horse farms using 5 different methods of calculating faecal egg count reduction. Equine Vet. J. 30, 289-293.
Döpfer, D., Kerssens, C.M., Meijer, Y.G.M., Boersema, J.H., Eysker, M., 2004. Shedding consistency of strongyle-type eggs in Dutch boarding horses. Vet. Parasitol. 124, 249-258.

Drudge, J.H., Elam, G., 1961. Preliminary observations on the resistance of horse strongyles to phenothiazine. J. Parasitol. 47, 38-39.

Eysker, M., Bakker, J., Berg, M., van de Doorn, D.C.K., van Ploeger, H.W. 2007. The use of age-clustered pooled faecal samples for monitoring worm control in horses. Vet. Parasitol. 151, 249-255.

Herd, R.P., 1986. Epidemiology and control of equine strongylosis at Newmarket. Equine Vet. J. 18, 447-452.

Lichtenfels, J.R., Kharchenko, V.A., Dvojnos, G.M., 2008. Illustrated identification keys to strongylid parasites (strongylidae: Nematoda) of horses, zebras and asses (Equidae). Vet. Parasitol. 156, 4-161.

Lyons, E.T., Tolliver, S.C., Ionita, M., Lewellen, A., Collins, S.S., 2008. Field studies indicating reduced activity of ivermectin on small strongyles in horses on a farm in Central Kentucky. Parasitol. Res. 103, 209-215.

Lyons, E.T., Tolliver, S.C., Collins, S.S., 2009. Probable reason why small strongyle EPG counts are returning 'early' after ivermectin treatment of horses on a farm in Central Kentucky. Parasitol. Res. 104, 569-574.

Ministry of Agriculture Fisheries and Food (MAFF), 1986. Manual of Veterinary Parasitological Laboratory Techniques: Reference Book 418, third ed. HMSO Books, London.

Molento, M.B., Antunes, J., Bentes, R.N., Coles, G.C., 2008. Anthelmintic resistant nematodes in Brazilian horses. Vet. Rec. 162, 384-385.

Osterman Lind, E., Rautalinko, E., Uggla, A., Waller, P., Morrison, D.A., Höglund, J., 2007. Parasite control practices on Swedish horse farms. Acta Vet. Scand. 49, 25.

Thienpont, D., Rochettte, F., VanParijs, O.F.J., 2003. Diagnosing Helminthiasis by Coprological Examination, 3rd ed. Janssen Research Foundation, Belgium.

Wyk van, J.A., 2001. Refugia-overlooked as perhaps the most potent factor concerning the development of anthelmintic resistance. Onderstepoort J. Vet. Res. 68, 55-67.

Von Samson-Himmelstjerna, G., Fritzen, B., Demeler, J., Schurmann, S., Rohn, K., Schnieder, T., Epe, C., 2007. Cases of reduced cyathostomin egg-reappearance period and failure of Parascaris equorum egg count reduction following ivermectin treatment as well as survey on pyrantel efficacy on German horse farms. Vet. Parasitol. 144, 74-80.

Von Samson-Himmelstjerna, Traversa, D., Demeler, J., Rohn, K., Milillo, P., Schurmann, S., Lia, R., Perrucci, S., Frangipane di Regalbono, A., Beraldo, P., Barnes, H., Cobb, R., Boeckh, A., 2009. Effects of worm control practices examined by a combined faecal egg count and questionnaire survey on horse farms in Germany, Italy and the UK. Parasites Vectors $2, \mathrm{~S} 3$.

Xiao, L., Herd, R.P., Majewski, G.A., 1994. Comparative efficacy of moxidectin and ivermectin against hypobiotic and encysted cyathostomes and other equine parasites. Vet. Parasitol. 53, 83-90. 